\title{
End of Life Decision: We are not Playing God?
}

\author{
Wan Khairina WMNa ${ }^{a}$ Ngow HA \\ a Hospital Pantai Ampang, Pandan Indah, Ampang, Malaysia \\ ${ }^{b}$ Department of Internal Medicine, Kulliyyah of Medicine, International Islamic University Malaysia
}

\begin{abstract}
Advances in neonatal care now enable more infants to be kept alive despite clear clinical evidence of inevitable or imminent death on a life-support system. It is therefore no longer acceptable to the society that a patient is left to die in the hospital, without any form of treatment or intervention. We report a case of severe birth asphyxia, hypoxic-ischemic encephalopathy, neonatal seizures and left cephalohematoma. In spite of initial successful resuscitation, the infant could not survive until all possible methods of treatment were exhausted. This case illustrates one of many examples of the process involved in dealing with ending of life decision in a condition considered as futile.
\end{abstract}

KEYWORDS: Birth asphyxia, resuscitation, life support system, end of life decision, medical futility.

\section{INTRODUCTION}

In the enthusiasm of saving lives, medical personnel often merely postpone death and overlook the impact of sustaining futile treatment on the patient, the family, the resources and the society. On the other hand, the family may wish for their child to be saved no matter how bad the prognosis might be. When the question of stopping ineffective treatment of such infants arises, adequate counselling of the parents, together with giving them sufficient time for discussions with their religious and family members, is the most crucial part of the decision-making process, as we wish to highlight in this case report.

\section{CASE REPORT}

A 23-year-old primigravida was admitted in labour at 40 weeks and 2 days gestation. The labour was complicated by Type 1 deceleration and fetal bradycardia on cardiotocogram at the second stage. A baby girl was born shortly with tight loops of umbilical cord around her neck. The baby had no breathing effort, and heart beat thus was vigorously resuscitated by the paediatric team.

Corresponding author:

Dr Harris Ngow Abdullah, Associate Professor, Consultant Physician and Cardiologist

Department of Internal Medicine

Kulliyah of Medicine

International Islamic University Malaysia

PO BOX 141

25710 Kuantan

Pahang Malaysia

Tel: $609-5132797$

Fax: 609-513 3615

Email: harrisngow@gmail.com
After intubation and administration of Adrenaline via the endotracheal tube, the heart beat was audible at 5 minutes of life, although it was still weak. Further resuscitation with normal saline bolus and sodium bicarbonate was required. The Apgar score was 0 at 1 minute, 0 at 5 minutes, 0 at 10 minutes, 2 at 13 minutes, 3 at 15 minute and 4 at 20 minutes. The cord blood gas done showed a severe metabolic acidosis.

In the neonatal intensive care unit, the baby was supported by the mechanical ventilation. The vital signs were near normal with blood pressure of $79 / 48$, heart rate $167 / \mathrm{min}$, oxygen saturation $99 \%$ and temperature $35.8 \mathrm{C}$. Physical examination revealed the absence of spontaneous respiration and movement. There was no eye opening with constricted, unreactive pupils. At 1 hour, the baby developed intractable seizure, which required multiple loading with intravenous phenobarbitone and phenytoin.

Initial investigations showed persistent metabolic acidosis and elevated cardiac enzymes; troponin $\mathrm{T}$ was $0.09 \mathrm{ng} / \mathrm{dl}$ and CKMB was 12.5umol/dl. Renal and liver functions were impaired. Ultrasound of the brain showed cerebral oedema, and the chest X-ray revealed a right pneumothorax. The baby was given a dose of IV Mannitol $10 \%$ and chest tube was inserted to drain the pneumothorax.

The baby also needed some ionotropic support and antibiotics for suspected sepsis on the following days. Despite improvement in clinical parameters and biochemical changes thereafter, the neurological impairment remained. Apart from spontaneous irregular breathing the baby remained obtunded. Parents had been updated of the baby's condition in multiple discussions. After almost a week, the discussion with the parents centred around treatment 
futility and de-escalation of therapy. An electroencephalogram at day 6 of life showed generalized burst suppression pattern with right centro-temporal and left temporal seizure foci.

After 2 weeks on the mechanical ventilation without showing any neurological improvement, a joint decision was made to withdraw the life support. The patient succumbs to the severe birth asphyxia few hours later.

\section{DISCUSSION}

This case report illustrates a common clinical scenario of severe birth asphyxia. The situation was not only difficult and traumatic on the parents but also tough and challenging for the managing team. In spite of initial successful resuscitation, the infant could not survive until all possible methods of treatment were exhausted.

Decision of withholding or withdrawal of life-sustaining treatment in children is often a difficult, contentious and emotive subject to discuss. Withholding is a process where there is no further escalation of treatment, even if it is medically indicated and doing so might prolong the life of a child. On the other hand, withdrawal is the active process of removing lifesustaining treatment (LST) for example, mechanical ventilation or inotropic support. These two processes are ethically and morally acceptable when the lifesustaining treatment is considered futile. ${ }^{1}$

It is always difficult to draw a line and to choose with holding or to institute treatment and later to withdraw in a condition that is considered futile. Once lifesustaining treatment has been instituted, some paediatricians and parents find withdrawal is psychologically and emotionally more difficult. On the other hand, the advantage of this option is to alleviate the sense of guilt for not doing the best for the child. The parents who opt for withdrawal of the treatment usually want some reassurance that everything possible has been done for the child and to prolong the life is merely prolonging the suffering of the child. ${ }^{1}$ As in our case, it took them several days to come to the decision to withdraw the life support.

Once treatment is futile, it is difficult for the managing clinicians as well as the parent to decide whether it is in the best interest of the patient to withhold or withdraw treatment.

The ethical, moral, religious and legal issues play important roles in influencing the decision. The Royal College of Paediatric and Child Health proposed a guideline in 1998 to ease the clinicians as well as the legislator in this matter. ${ }^{1}$ There are five situations in which withdrawing or withholding life-sustaining treatment is considered ethically and legally acceptable.
The five situations are;

1. The brain dead child
2. The "Permanent Vegetative State"
3. The "No Chance" situation
4. The "No Purpose" situation
5. The "Unbearable" situation

The definition of a brain dead has evolved through time. In 1967, The American Electroencephalographic Society concluded that the electro-cerebral silence can be used as a criterion of brain death, and thus defined it as the electro-cerebral silence with complete unresponsiveness, apnoea, absent cephalic reflexes, and inability to maintain circulation without artificial means. This definition was supported by the Ad Hoc Committee of the Harvard Medical School in 1968. It was amended in 1975 by the American Neurological Association that the criteria may be inapplicable for children under 5 years old due to the immaturity of their nervous system, and this was supported by the President's Commission-determination of Cerebral Death in 1981. In 1987, the Guidelines of the Task Force for the Determination of Brain Death in Children were introduced.

The second situation that withdrawal or withholding treatment is acceptable is the "permanent vegetative" state. ${ }^{2}$ The child who develops permanent vegetative state following insults such as trauma or hypoxia, is reliant on others for all care and does not react or relate with the outside world. A useful test to determine this is the somatosensory evoked potential where there will be absent of cortical peaks. ${ }^{3}$

The "no chance" situation is a condition when a child has such severe disease that life-sustaining treatment simply delays death without significant alleviation of suffering. This is synonymous with an imminent death rationale. ${ }^{1}$ Treatment to sustain life is inappropriate in this situation.

The "no purpose" situation is a condition in which the patient may be able to survive with treatment, but the degree of physical or mental impairment will be so great that it is unreasonable to expect parents to bear it. ${ }^{1}$ However, in this situation, conflict may occur between the physician and the family. An example is the David Glass case, a 12-year-old boy with spastic quadriplegia and blindness who developed severe pneumonia was not resuscitated by the medical staff at St. Mary Hospital, Portsmouth. The parents had asked for the court order to continue the lifesustaining treatment, but had lost the case. ${ }^{4}$

The "unbearable situation" is where the child or the family feels that in the face of progressive illness, further treatment is unacceptable. They wish to have particular treatment withdrawn or to refuse further treatment irrespective of the medical opinion that it may be of some benefit. ${ }^{1}$ An example is refusing salvage chemotherapy in some oncology patients. The 
child as illustrated in this case report may fit in either the "No Chance" situation or the "No Purpose" situation.

The practice of withholding or withdrawal of lifesustaining treatment is well recognized in the Neonatal Intensive Care Units worldwide. In the United Kingdom, it may occur in about $70 \%$ of deaths in the NICU. ${ }^{1}$ There are several known conditions in which the practice of withholding or withdrawal is accepted worldwide. They are congenital abnormality that is incompatible with survival, for example, anencephaly, or a baby born with a confirmed gestation of 23 weeks or less or a baby, who has suffered severe birth asphyxia, in whom investigations reveal profound brain damage.

In a study done locally, it was found that the limitation of treatment is the most common mode of death in the Paediatric ICU. They have found that 68 out of 148 ( 46\%) died after such decision. ${ }^{5}$ The "No Chance" situation or imminent death was the most commonly cited justification for the limitation of treatment. The "No purpose" situation was cited in only 8 patients. There were only 19 patients who fulfilled the criteria of brain death. 12 out of 19 brain-dead patients were extubated, as the other seven families had refused to make such a decision. Active withdrawal was only performed in seven patients (5\%) who did not fulfil the criteria for brain death. ${ }^{5}$

In another study done in the University of California, $73 \%$ of deaths in the Intensive Care Nursery were the result of withholding or withdrawal of treatment. ${ }^{2}$ They also found that withdrawal of treatment was more commonly done compared to withholding treatment. In $74 \%$ of deaths resulting from the decision, continued treatment considered futile in the face of imminent death. In $23 \%$ of death after such decision, quality of life of the child was the main concern.

It could be argued that treating futile conditions may be economically exhausting, which poses the dilemma of modern healthcare, where rigorous effort and expense may not be cost effective. There are some studies on the cost of treating futile conditions in ICU. In an adult ICU study, it was estimated that the potential savings of $\$ 2-5$ million per year could be achieved by identifying the care that is futile, and another study found that treating futile patients predicted to die in ICU may cost up to $\$ 210,423$ per survivor. ${ }^{6}$ However, Sachdeva et al showed that these potential cost savings might not apply to pediatric ICU population as only small amounts of resources were expended on futile care. ${ }^{6}$ In the earlier study by Goh and Mok (2001), the paediatricians might be more readily recognizing futile care early and dealing with it in an ethically appropriate manner and thus resulted in the majority of deaths involved some form of withholding or withdrawal of therapy. ${ }^{5}$
However, restricting care in the interest of cutting down the cost is not ethically appropriate and may lead to misuse of the concept of futility. The wide use of treatment limitation may limit the amount of care given to the critically ill children.

As in our case, the decision could not be made in a short time as the family took sometimes to understand the situation and undergo the process of grief. This decision is influenced by many factors, mainly the severity of the child's condition itself, poor response to medical therapy, and poor quality of life. Apart from that, cultural, religious belief and social background may play important roles. As in the case above, the opinion of the elder member of the family was important for the parents, and this may reflect the cultural or religion influences in the matter of life and death.

In the study by Goh AY (1999), extended family members were almost always present during the discussions and families often requested the pediatrician to do what was best for their child. ${ }^{7}$ In children who fulfill the brain death criteria, withdrawal of treatment, including extubation was proposed; however, 7 of 19 refused extubation and opted for limitation of treatment. All the refusals were by Malays. The cited reasons for refusals were differences in recognition and acceptance of brain death as actual death. In all cases, including the non brain dead patients, there were 14 out of 24 parents who refused withdrawal and instead chose limitation of treatment, with nine of 11 were Malays, three of six were Chinese, and two of four cases were Indians. The reasons were unclear in most cases, but this reflects that every ethnicity has its own beliefs and values regarding death.

Apart from brain death, care restrictions were often based on the no chance situation, occurring after failure of therapeutic interventions, with death following promptly after placement of such orders. The no purpose situation might be more difficult where there is uncertainty in predicting future quality of life, and what constitutes the intolerable handicap also differs between individuals. The above patient in this case summary might fit the description of the no chance situation, where being dependent on the ventilator, extubation led to the death of the child. Severe hypoxic ischemic encephalopathy (HIE) is known to carry an unfavourable outcome, and no single indicator is able to predict with absolute certainty the outcome from coma. A prospective cohort study by Mandel of 57 children who were mechanically ventilated for HIE throughout a 3-year period, showed a mortality rate of $54 \% .^{8}$ In other studies of case mix of traumatic and non traumatic $\mathrm{HIE}$, the mortality rate ranged between $34 \%$ and $73 \%$. However, there was no study done on the quality of life of the survivors, and thus it is still arguable whether the decision of prolonging the lives of some of the survivors was ethically acceptable. 
In the end, we have to go back to our basic obligation that is to act in the child's best interest, and continued treatment should not be forced when hope for the benefit is uncertain. We harm if we over-treat, and we harm if we are too passive. It is also important that communication with the parents should be maintained throughout the process to support and collaborate in the decision making as well as to avoid later disagreement or unrealistic expectation on both parties.

Although the limitation of care is not widely discussed in the public, especially in a country like Malaysia, there will be a time when our society will be better informed regarding medical ethics. The RCPCH guideline provides a reasonable framework for the practicing physician in Malaysia; however, a local guideline needs to be set up considering our multiracial society with multiple sets of values and beliefs. Our legal system is somewhat different from the Western court and thus may be conflicting with the Western guideline. In Malaysia, religious and cultural issues often play a more vital role in decision making by parents and physicians than economic considerations. The relationship between patient and physician is one of the traditional paternalism, based on the principles of goodness and kindness.

We conclude that where science and technology are of little or no help, it is necessary to take decisions on vital support limitation or withdrawal of therapy in neonates based on published scientific evidence after discussion with the parents. Whatever we may do; the ultimate fact is that God determines the time of death, and we are only God's instruments for the good of the patient.

\section{REFERENCES}

1. Royal College of Paediatrics and Child Health. Withholding and withdrawal of life-sustaining treatment in children: a framework for practice. 2nd Edition, 2004. [online]. Available at: http://www.bapm.org/publications/ documents/guidelines/Withholding\&withdrawing_ treatment.pdf

2. Guidelines for the determination of brain death in children. Task Force for the Determination of Brain Death in Children. Arch Neurol 1987; 44:587-8.

3. Beca J, Cox PN, Taylor MJ, et al. Somatosensory evoked potentials for prediction of outcome acute severe brain injury. J Pediatr 1995; 126:44-6.

4. Tournay AE. Withdrawal of medical treatment in children. West J Med 2000; 137:407-11.

5. Goh AY, Mok Q. Identifying futility in a paediatric critical care setting: a prospective observational study. Arch Dis Child 2001; 83:265-8.

6. Sachdeva RC, Jefferson LS, Coss-Bu J, Brody BA. Resource consumption and the extent of futile care in a paediatric intensive care unit setting. $\mathrm{J}$ Pediatr 1996; 128:742-7.

7. Goh AY, Lum LCS, Chan PWK, et al. Withdrawal and limitation of life support in paediatric intensive care. Arch Dis Child 1999; 80:424-8.

8. Mandel R, Martinot A, Delepoulle F, et al. Prediction of outcome after hypoxic-ischemic encephalopathy: A prospective clinical and electrophysiological study. J Pediatr 2002; 14: 45-50. 